\title{
CARACTERIZACIÓN DE LA COBERTURA VEGETAL DENTRO DE LA FRANJA DE PROTECCIÓN DEL RÍO COPEY, JACÓ, PUNTARENAS, COSTA RICA
}

\section{CHARACTERIZATION OF VEGETATION COVER AND LAND USE WITHIN THE BUFFER ZONE OF COPEY RIVER, JACÓ, PUNTARENAS, COSTA RICA}

\author{
David Mattey-Trigueros ${ }^{1}$ \\ Jonathan Navarro-Picado ${ }^{2}$ \\ Priscilla Obando-Rodríguez ${ }^{3}$ \\ Alicia Fonseca-Sánchez ${ }^{4}$ \\ Christian Núñez-Solís ${ }^{5}$ \\ Universidad Nacional de Costa Rica, Costa Rica
}

1 Escuela de Ciencias Biológicas, Universidad Nacional. Correo electrónico: davidmattey@gmail.com

2 Escuela de Ciencias Biológicas, Universidad Nacional de Costa Rica. Correo electrónico: jon90np@ gmail.com

3 Escuela de Ciencias Biológicas, Universidad Nacional de Costa Rica. Correo electrónico: pris.obando@ gmail.com

4 Laboratorio de Hidrología Ambiental, Escuela de Ciencias Biológicas, Universidad Nacional. Correo electrónico: alicia.fonseca.sanchez@una.cr

5 Laboratorio de Hidrología Ambiental, Escuela de Ciencias Biológicas, Universidad Nacional. Correo electrónico: christian.nunez.solis@una.cr

Fecha de recepción: 27 de julio de 2016

Fecha de aceptación: 07 de octubre de 2016 
David Mattey-Trigueros, Jonathan Navarro-Picado, Priscilla Obando-Rodríguez, Alicia Fonseca-Sánchez, Christian Núñez-Solís. Characterization of vegetation cover and land use within the buffer zone of Copey river, Jacó, Puntarenas, Costa Rica.

\title{
RESUMEN
}

Los ríos son de los ecosistemas más afectados por las actividades del ser humano; por ello, es necesario evaluar las condiciones de los mismos y su entorno; por esto el objetivo de este estudio es caracterizar la cobertura vegetal y usos de suelo dentro de la franja de protección a lo largo del cauce río Copey. En dos visitas de campo (2013) se recorrió el cauce del río generando puntos de control geoposicionados de las categorías de usos de suelo, variaciones en la vegetación y toma de fotografías, luego por medio de fotointerpretación de imágenes a juicio de expertos se generaron tres mapas, además de gráficos de caracterización de la vegetación de tres zonas. Se categorizaron 11 tipos de uso de suelo, en donde predomina el bosque denso. En la parte alta predomina la cobertura boscosa, en la parte media pastizales con borde arbustivo y en la parte baja infraestructura urbana. La principal conclusión es que existe gran área sin infraestructura urbana ni vegetación, por lo que es de gran potencial para esfuerzos de restauración.

Palabras clave: cobertura vegetal, río Copey, uso de suelo, vegetación de ribereña, zona de protección.

\begin{abstract}
Rivers are considered one of the ecosystems most affected by humans. This is why it is important to evaluate the conditions of rivers and their environment. The purpose of this research is to characterize the vegetation cover and land use within the buffer zone along the Copey river. In two field trips (2013) we hit the river course to generate control geopositioned points coverage, vegetation variations and photographing. Then, we used the photo-interpretation method, by the expert judgment, and then generated three coverage maps. Additionally, we generated DAP, characterization height of trees in tree river zones. We categorized 11 coverage types, where the predominant coverage was the dense forest. The upper side is the one with the greatest forest cover. Shrubby grasslands edge predominates in the middle side, and the lower side begins to present urban infrastructure. We concluded that there is a large area devoid of vegetation, without urban infrastructure, which indicates that it is one of the areas with the greatest potential for restoration efforts.
\end{abstract}

Keywords: Vegetation coverage, Río Copey, land use, riparian zone.

\section{Introducción}

Actualmente, entre los ecosistemas más afectados por las actividades antrópicas se encuentran los ríos y nacientes, debido a cambios en el uso de suelo en las zonas ribereñas que generarán diversos efectos como aumento en los procesos de erosión de los suelos, incremento de materia orgánica que entra a los sistemas acuáticos, arrastre de sedimentos, eutrofización, entre otros. Esto se acelera por aspectos como el tipo de suelo, pendiente del sitio, geología y precipitación (Kutschker et al., 2009; Cardona, 2003).

Para mitigar estos efectos, es importante proteger y restaurar las zonas ribereñas que representan áreas de protección para el recurso hídrico, ya que cumplen una función de "amortiguador" (Granados-Sanchez et al., 2006) debido a sus funciones como el retener contaminantes, sedimentos y nutrientes, además de mejorar la calidad del agua, estabilizar 
las orillas, reducir la velocidad de la corriente, evitar desbordamientos y brindar zonas de paso favorables para la vida silvestre y la conectividad biológica. Así que su importancia no solo radica en un aspecto hidrológico y biológico, sino que también involucra la protección de un recurso a futuro y la mitigación de probables desastres naturales (Gayoso y Gayoso, 2003; Granados-Sanchez et al., 2006).

En los procesos de gestión integrada del recurso hídrico se deben de considerar estas zonas como un componente fundamental (Gayoso y Gayoso, 2003), esto se refleja en la protección que tienen estas áreas en el país bajo la Ley Forestal, tanto en zonas urbanas como en zonas rurales (Ley Forestal $\left.N^{\circ} 7575,1996\right)$. Sin embargo, estos parámetros estipulados por la legislación no siempre se respetan, de ahí la importancia de caracterizar las zonas ribereñas para planes de ordenamiento territorial e identificar zonas vulnerables para la acertada toma de decisiones, que generen un mejoramiento en las condiciones de ríos, cuencas y el recurso hídrico en general (Programa Araucaria, 2001).

A raíz de lo anterior, el conocer el estado de estas zonas en un cantón como el de Garabito que experimenta un gran desarrollo urbano y turístico, es fundamental para presentar un adecuado manejo del recurso hídrico y evitar un aumento en las actuales presiones sobre las aguas superficiales y subterráneas del río Copey. Por lo cual, el objetivo del siguiente estudio es caracterizar la cobertura vegetal y uso del suelo dentro de la franja de protección según la ley Forestal a lo largo del cauce río Copey en Garabito, Puntarenas.

\section{Área de estudio}

La investigación se realizó a lo largo de la ribera del río Copey, en el distrito de Jacó, cantón de Garabito, en la provincia de Puntarenas, Costa Rica. La ubicación del área de estudio correspondió a las zonas ribereñas del río Copey, en un segmento que inició en la parte alta (coordenadas $9^{\circ} 39^{\prime} 22.18^{\prime \prime} \mathrm{N}-84^{\circ} 34^{\prime} 46.98^{\prime \prime} \mathrm{O}$ ) y hasta la zona de desembocadura del río (9`36’53.25”N-84³7’53.49”O) (Mapa 1). Se realizó el análisis de cobertura vegetal de la zona ribereña protegida, esta se estimó a partir de los lineamientos de la Ley Forestal 7575, la cual dicta en el artículo 33 sobre áreas de protección de ríos: "Una franja de quince metros en zona rural y de diez metros en zona urbana, medidas horizontalmente a ambos lados, 
David Mattey-Trigueros, Jonathan Navarro-Picado, Priscilla Obando-Rodríguez, Alicia

Fonseca-Sánchez, Christian Núñez-Solis. Characterization of vegetation cover and land use

within the buffer zone of Copey river, Jacó, Puntarenas, Costa Rica.

en las riberas de los ríos, quebradas o arroyos, si el terreno es plano y de cincuenta metros horizontales si el terreno es quebrado".

Mapa 1. Ubicación del área de estudio

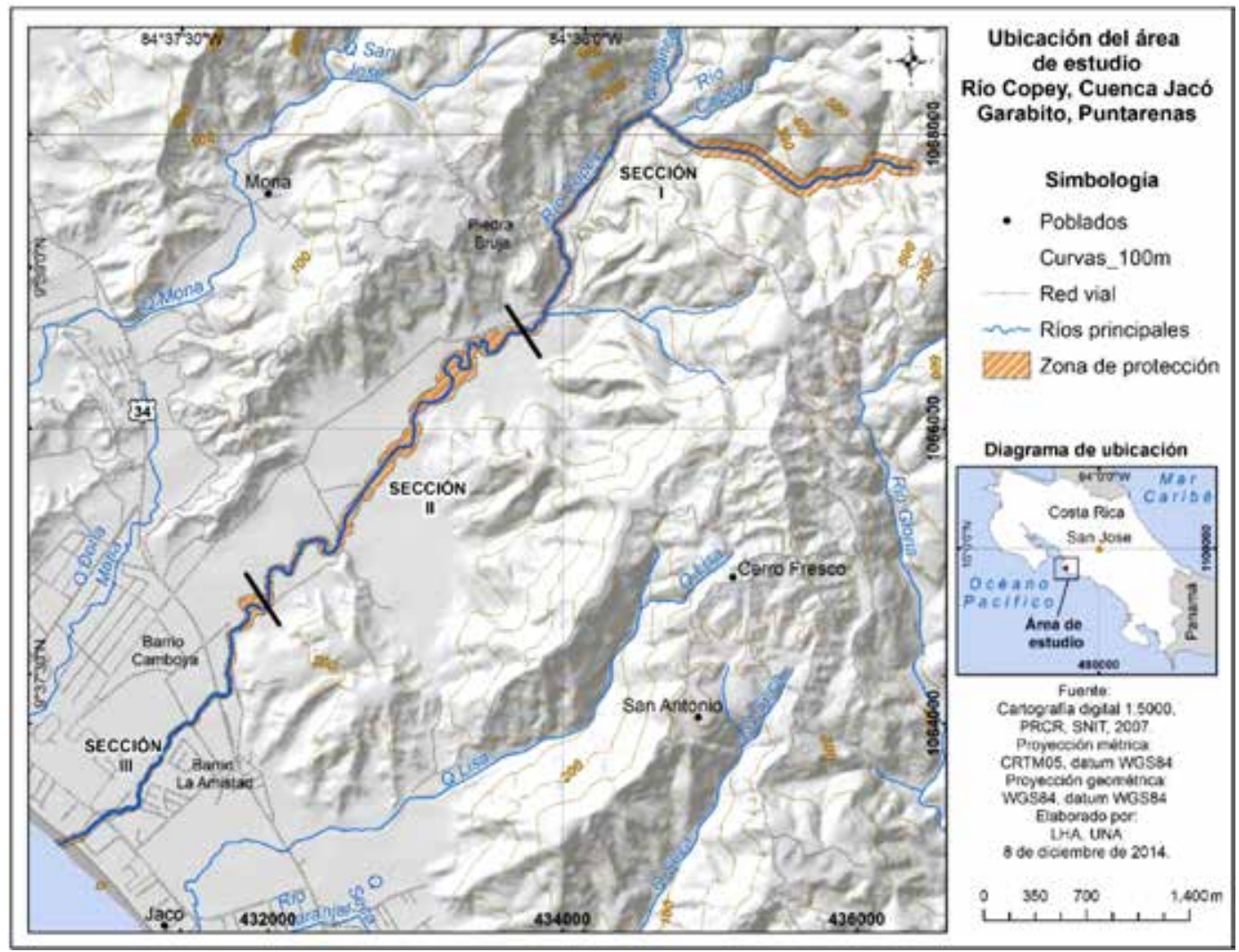

Fuente: Elaboración propia a partir de puntos de GPS (2016).

El cauce principal inicia a los $550 \mathrm{msnm}$ y finaliza a los $0 \mathrm{msnm}$ con la desembocadura en el Océano Pacífico. Este río cruza por el centro del casco urbano de la ciudad de Jacó y se utiliza para extracción de agua para el riego de cultivos y bebedero de ganado; además, en la parte alta se ubica la planta de captación y tratamiento de agua potable del Instituto de Acueducto y Alcantarillados (A y A). Estas características lo convierten en uno de los recursos de mayor importancia para la población local. 


\section{Marco Teórico-Conceptual}

Los bosques ribereños se ven sujetos a una condición cambiante debido a procesos fluviales, que proporcionan el flujo de materia y energía que producen una flora con características propias del lugar, diferente tanto estructural como funcionalmente de bosques en ecosistemas adyacentes. Lo anterior hace que cumplan un papel importante como proveedores de alimento, corredores biológicos, reguladores de temperatura, evitan la erosión y como filtro de nutrientes y materiales contaminantes (Sirombra y Mesa, 2010). La vegetación presente en una zona tan frágil y variable como la ribera, proporciona por medio de su sistema radical un ambiente acuático menos eutrofizado y una carga de sedimentos disminuida (Peraza, 2009).

Las actividades humanas también obtienen beneficios de estos ecosistemas, por ejemplo, en fincas ganaderas se conoce el efecto que tiene la vegetación de estas zonas en una disminución tanto de escorrentía superficial como de arrastre de nutrientes y de compuestos nitrogenados, además de servir como una fuente de control indirecto de plagas que pueden afectar distintos cultivos (Chará et al., 2011 y Granados-Sánchez et al., 2006).

De igual manera, la fauna silvestre se beneficia de los bosques ribereños, ya que representan uno de los principales corredores para el paso de vida silvestre y se ha documentado por ejemplo, en el estado de Washington según Ceccon (2003), que más del $80 \%$ de las poblaciones de animales silvestres usan el bosque ribereño en algún momento de su vida. La funcionalidad de los bosques de ribera como refugio a la biodiversidad, es debido a la presencia del recurso agua, fundamental en todo ser vivo; además, son menos propensos a incendios forestales que bosques circundantes por la cualidad de inundación temporal, minimizando la probabilidad de quemar la vegetación (Ceccon, 2003).

Por otra parte, estudios relacionados con la diversidad en estos bosques demuestra que el ancho debe de ser al menos de 30 metros e inclusive en algunos casos hasta de 100 metros, para generar suficientes recursos que permitan a algunas especies utilizarlos como corredores biológicos donde se permita la conectividad. Además, es importante también para las especies que pueden llegar a cumplir todo su ciclo de vida utilizando únicamente los recursos provistos en esta franjas sin colonizar parches boscosos de mayor tamaño (Eichner, 2002). 
Sin embargo, para lograr un verdadero aumento en la diversidad en estas zonas se debe de tratar de proteger y restaurar dichos ecosistemas, ya que el ancho de las mismas influye directamente sobre la diversidad que puedan albergar, así, zonas más anchas se espera que sean utilizadas por mayor número de especies (Arcos et al., 2007). Además, la vegetación presente en ellas propician importantes recursos para la sustentación de poblaciones de especies acuáticas de vertebrados; de igual manera, organismos invertebrados se verán beneficiados. Lo anterior, se ve influenciado por la presencia de bosques ribereños debido al aporte de frutos que sirven de alimento, además de generar condiciones microclimáticas que regulan la temperatura y otras características físicas del agua, generación de refugios en las zonas de inundación, entre otros (Arcos, 2005).

Según Elosegi y Díez (2009) existen tres aspectos importantes a tomar en la determinación de la funcionalidad y estado óptimo de estas asociaciones vegetales; a saber, primero, la extensión, anchura y continuidad longitudinal de la vegetación, después la conectividad entre el cauce y las orillas y por último la composición, madurez y estructura de la vegetación de ribera.

En los ecosistemas acuáticos existe una gran cantidad de impactos que afectan el bienestar del mismo, entre ellos se encuentran la degradación de la calidad del agua, problemas de la entrada de luz solar, debido a la gran acumulación de sedimentos, lo que puede generar una reducción de la fotosíntesis, así como que los sedimentos en ocasiones cubren las piedras del río, las cuales son utilizadas por algunos peces para colocar sus huevos (Broadmeadow, 2004 y Ceccon, 2003).

Entre las problemáticas que se asocian a estos ecosistemas se encuentra la fuerte exposición a actividades antrópicas, esto debido a la creciente urbanización y a la falta de ordenamiento territorial, lo cual en gran parte provoca una pérdida de biodiversidad, invasiones biológicas y contaminación por efluentes domésticos e industriales (Viana et al., 2005).

Las altas concentraciones de algunos elementos como el fósforo, favorecen el rápido proceso de eutrofización, el cual es provocado por el exceso de nutrientes en el agua, que conlleva al incremento de plantas acuáticas de vida corta, las cuales al morir sufren del proceso de descomposición aeróbica, lo cual afecta al ecosistema en general, ya que el gran consumo de oxígeno durante este proceso, afecta el desarrollo de otras especies e incluso de las mismas plantas (Ceccon, 2003). 
La falta de hacer cumplir la ley de protección a la franja ribereña ha conducido a que las personas construyan sus casas o ranchos en las orillas de los ríos, lo cual genera problemas de salud ecosistémica, así como una mayor exposición a problemas de pérdida de sus pertenencias debido a las crecidas y otras razones.

\section{Legislación relacionada con los bosques ribereños}

En Costa Rica los bosques ribereños se encuentran protegidos por la ley forestal, en su capítulo IV referente a la protección forestal, dentro del artículo 33 para áreas de protección. En el cual, se declaran como zonas de protección forestal franjas de quince metros para zona rural y diez metros en zona urbana a ambos lados de los ríos. Además, en presencia de terrenos quebrados (Son aquellos que tienen una pendiente promedio superior al cuarenta por ciento. (Reglamento a la Ley Forestal, 1997)), se debe dejar una distancia de cincuenta metros en la ribera de los ríos (Ley Forestal $\mathrm{N}^{\circ} 7575,1996$ ).

En cuanto al artículo 58 de dicha Ley, se hace referencia a que se interpondrán tres meses de prisión, a las personas que invadan un área de conservación o protección. Específicamente se explica: "Invada un área de conservación o protección, cualquiera que sea su categoría de manejo, u otras áreas de bosques o terrenos sometidos al régimen forestal, cualquiera que sea el área ocupada; independientemente de que se trate de terrenos privados del Estado u otros organismos de la Administración Pública o de terrenos de dominio particular. Los autores o partícipes del acto no tendrán derecho a indemnización alguna por cualquier construcción u obra que hayan realizado en los terrenos invadidos".

\section{Marco Metodológico}

Se determinó la cobertura vegetal del río Copey, con el método de fotointerpretación de imágenes, para esto se utilizó ortofotos del Proyecto Regularización Catastral y Registral (PRCR) para Costa Rica entre 2007-2008 a escala 1:5000. Las fotografías fueron interpretadas a juicio de expertos y editadas en formato shapefile en el programa ArcGis 10.1. Se realizaron dos visitas de campo durante abril 2013, en las cuales se recorrió el cauce del río, para generar puntos de control geoposicionados de las coberturas, variaciones en la vegetación y toma de fotografías; con 
el fin de corroborar y actualizar las coberturas al 2013. Una vez rectificados los datos se editó cartográficamente en tres mapas los resultados, a escala 1:10000.

Las categorías de uso del suelo utilizadas para el análisis geoespacial y comprobación de campo, se describen en el cuadro 1, los cuales fueron tomados y ajustados a las condiciones específicas de nuestro sitio de muestreo del documento de evaluación de los recursos forestales del programa FAO (2010), con respecto a la categoría de bosque se utiliza como medida de diferenciación entre bosque denso y bosque ralo el procentaje de cobertura arbórea, así el primero debería ser terrenos con un procentaje mayor al $75 \%$, esto con el fin de realizar una caracterización más específica de la zona en cuestión.

\section{Cuadro 1. Categorías de uso del suelo presentes en río Copey, Jacó, Puntarenas.}

\begin{tabular}{|l|c|l|}
\hline $\begin{array}{c}\text { Categorías de uso del } \\
\text { suelo }\end{array}$ & Abreviatura & \multicolumn{1}{|c|}{ Descripción } \\
\hline Bosque Denso & (BD) & $\begin{array}{l}\text { Árboles altos, zonas muy quebradas, pocos sectores } \\
\text { con indicios de erosión o derrumbes de tierra y } \\
\text { zonas muy rocosas. }\end{array}$ \\
\hline Bosque Ralo & (BR) & $\begin{array}{l}\text { Zonas con árboles altura variable, pero diámetros } \\
\text { bajos en comparación con los de bosque denso, } \\
\text { presencia de indicios de erosión o derrumbes. }\end{array}$ \\
\hline Herbazal Arbolado & (HA) & $\begin{array}{l}\text { Arboles dispersos, zonas más alteradas, vegetación } \\
\text { baja y zonas abiertas. }\end{array}$ \\
\hline Herbazal & (H) & $\begin{array}{l}\text { Zonas de pastos, hierbas y arbustos bajos, sin árboles } \\
\text { o con muy baja cantidad y muy aislados. }\end{array}$ \\
\hline Infraestructura vial & (IV) & $\begin{array}{l}\text { Zona del río en la cual el río pasa por debajo del } \\
\text { camino o puente. }\end{array}$ \\
\hline Infraestructura urbana & (IU) & $\begin{array}{l}\text { Borde del río sin vegetación y presencia de } \\
\text { construcciones o edificaciones antrópicas. }\end{array}$ \\
\hline Pastos & (P) & Ribera del río dominado totalmente por gramíneas. \\
\hline $\begin{array}{l}\text { Pastizal con borde } \\
\text { arbustivo }\end{array}$ & (PBA) & $\begin{array}{l}\text { Ribera del río dominada de gramíneas y en los } \\
\text { bordes presencia de arbustos. }\end{array}$ \\
\hline Borde urbano arbolado & (BUA) & $\begin{array}{l}\text { Borde del río con presencia de edificaciones } \\
\text { antrópicas y arboles dispersos. }\end{array}$ \\
\hline Zona descubierta & (ZD) & $\begin{array}{l}\text { Incluye zonas de meandros y del cauce del río sin } \\
\text { lámina de agua presente. }\end{array}$ \\
\hline Playa & (Pl) & Zona más cercana a la desembocadura del río. \\
\hline
\end{tabular}

Fuente: tomado y modificado de FAO (2010). 
En los sitios con mayor cobertura boscosa se realizaron parcelas de $300 \mathrm{~m}^{2}(15 \times 20 \mathrm{~m})$. En total se muestrearon 3 coberturas (BD, BR y HA), para lo cual se establecieron 2 parcelas en cada una de ellas. Las mediciones consistieron en; el diámetro a la altura del pecho (DAP, 1,30 cm), la altura de los árboles, y cobertura del dosel en las cuatro esquinas y en el centro. También se calculó la pendiente en cada sitio.

\section{Resultados y Discusión}

La zona de protección equivale a un área total de $70 \mathrm{Ha}$ y que en términos porcentuales a partir del levantamiento de usos del suelo el bosque denso (BD) representa el número predominante con un $28 \%$ localizado principalmente en la parte alta en un sector donde la pendiente es mayor al $40 \%$ y por consiguiente $50 \mathrm{~m}$ lineales al río son la condición de protección. Un 19\% está caracterizado por herbazal arbolado (HA) un estado de uso que refleja degradación de la ribera con intervención antrópica presente en los espacios de actividad agrícola y ganadera. Las zonas descubiertas (ZD) componen un $17 \%$, estos espacios dejan al descubierto el cauce del río en áreas de alta productividad agrícola en la parte media y baja siendo vulnerable a la contaminación de aguas superficiales y subterráneas (Ver gráfico 1).

Gráfico 1: Área de cobertura (\%) de las categorías de uso de suelo sobre la zona de protección del Río Copey, Puntarenas, Costa Rica.

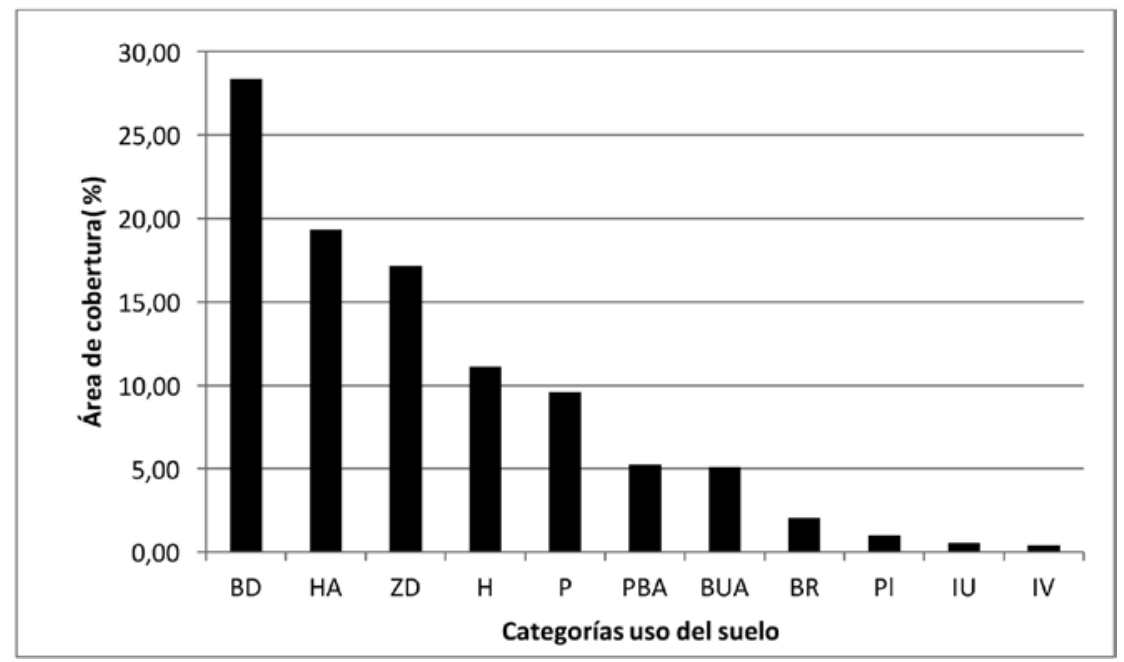

Fuente: Elaboración propia (2016). 
El uso de suelo predominante en la zona de estudio corresponde al BD; sin embargo, esto se presenta únicamente en la parte alta de la cuenca, ya que aguas más abajo se observan otros usos de suelo que proveen una menor cobertura vegetal, tales como ZD y HA, estas zonas pueden representar sitios con gran potencial para futuros esfuerzos de restauración tanto pasiva como activa, para estos esfuerzos se debe tomar en cuenta las actividades agrícolas y económicas que se generan en el sitio de estudio, ya que estas determinarán los principales usos y presiones sobre el recurso hídrico y la vegetación ribereña (Ortiz-Arrona et al., 2005).

En la sección I o la parte alta del río Copey se presenta una predominancia de bosque denso con un $61 \%$ del área, seguida por herbazal arbolado con un $31 \%$. La primera, es la zona menos impactada por las actividades antrópicas y que muestra un adecuado estado de protección de la ribera del río. Además, en este sector se localiza la planta de toma y tratamiento de aguas potables del AyA para el acueducto de Jacó, aspecto que determina la condición actual del sitio (Ver mapa 2).

Estas zonas presentan gran potencial, ya que tienen condiciones aptas para la recolonización de especies vegetales. Si se toma en cuenta que zonas como el BD pueden servir de banco de semillas, esto asegura la dispersión de especies adaptadas a la zona de estudio (Meli, 2003), por lo que es de suma importancia el proteger las zonas más altas del cauce de este río y sus alrededores.

Asimismo, la debida conservación y protección de la zona alta asegura que diferentes agentes antrópicos no perturben y degeneren las riberas del río y no las convierta en zonas altamente vulnerables. Se requiere considerar que cualquier actividad dentro de esta área con pendiente tan pronunciada podría generar consecuencias como erosión, derrumbes y eventuales daños a infraestructura tanto pública como privada. 
David Mattey-Trigueros, Jonathan Navarro-Picado, Priscilla Obando-Rodríguez, Alicia Fonseca-Sánchez, Christian Núñez-Solís. Caracterización de la cobertura vegetal dentro de la franja de protección del río Copey, Jacó, Puntarenas, Costa Rica.

Dentro de la franja de protección de la parte media del río (Ver mapa 3) predomina la cobertura de herbazal arbolado con un $29 \%$, mientras con un $28 \%$ la zona descubierta. Con lo cual se identifica la fuerte influencia de la actividad ganadera y agrícola con el cultivo de arroz, frijol y maíz. Además, una exposición directa del cauce a los diferentes agentes contaminantes tanto orgánicos nitrogenados por los excrementos de los animales como de pesticidas de los cultivos cercanos.

Mapa 2: Uso de suelo en la parte alta (Sección I), sobre la zona de protección del Río Copey, Jacó, Puntarenas, Costa Rica.

(135000

Fuente: Elaboración propia a partir de puntos de GPS (2016). 
Mapa 3: Uso de suelo en la parte media (Sección II), sobre la zona de protección del Río Copey, Jacó, Puntarenas, Costa Rica.

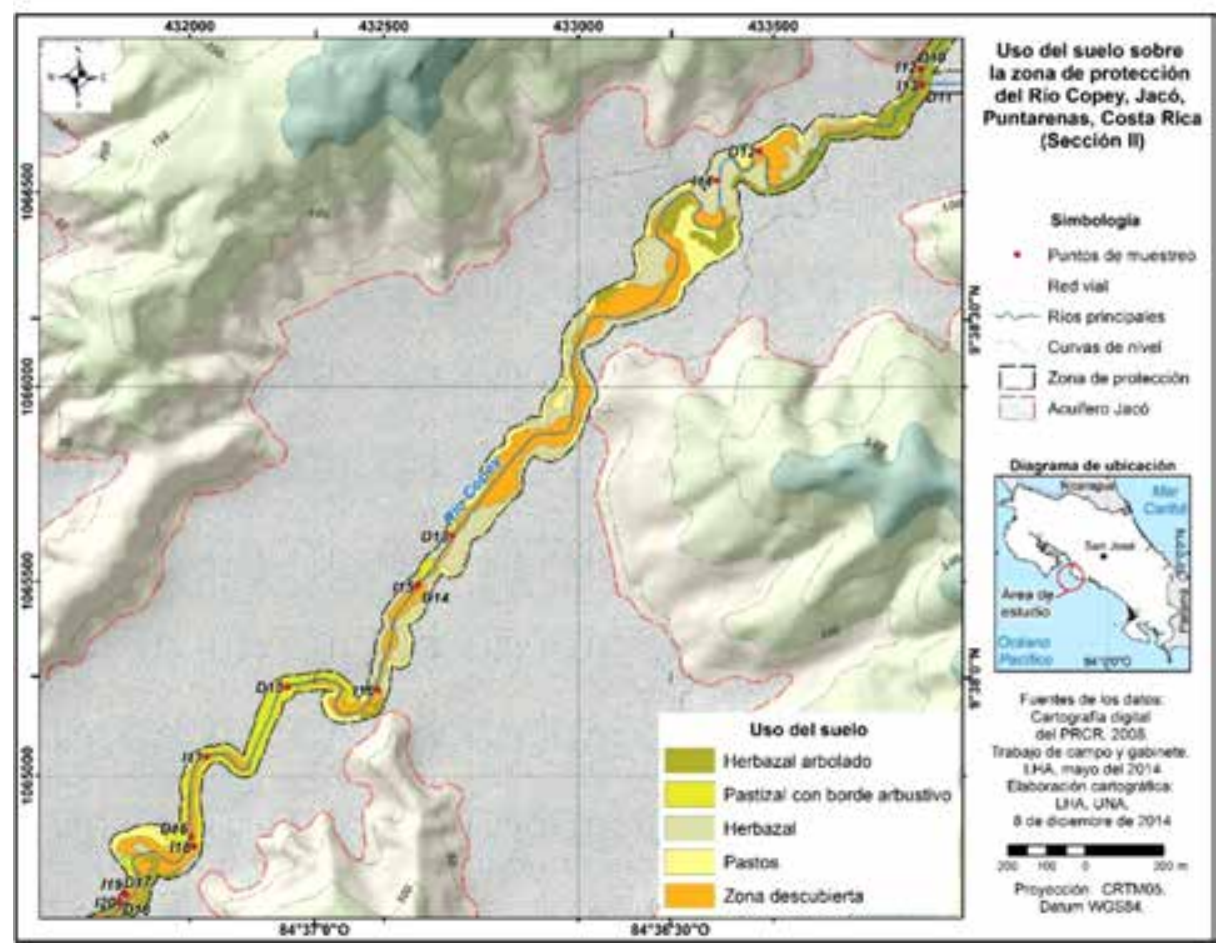

Fuente: Elaboración propia a partir de puntos de GPS (2016).

Con porcentajes menores y distribuidos en la sección II y III, usos caracterizados por la intervención antrópica son predominantes y que en conjunto tienen un alto potencial de impacto al ecosistema del río. Aguas abajo la cobertura boscosa pierde terreno y se irrespetan aún más el margen del cauce con actividades de tipo urbana, agrícola y ganadera que conllevan a una contaminación del río por botadero de basura clandestinos, disposición de aguas negras y servidas, lavadero de autos, entre otras.

Por otra parte, aproximadamente un $28 \%$ del cauce presenta una inclinación de pendiente por encima del $40 \%$, el resto se sitúa sobre la planicie aluvial con pendientes no mayores al $5 \%$, sobre esta zona el río genera meandros y sectores de inundación. Aspecto que incrementa las amenaza los pobladores ubicados dentro de las márgenes del río a causa de las crecidas y la degradación del mismo cauce a falta de vegetación (Ver mapa 3 y 4). 
Mapa 4: Uso del suelo en la parte baja (Sección III), sobre la zona de protección del Río Copey, Jacó, Puntarenas, Costa Rica.

(1)

Fuente: Elaboración propia a partir de puntos de GPS (2016).

En cuanto a la parte baja del río, aparecen infraestructuras urbanas, en forma de pequeños parches que en conjunto pueden ser altamente contaminantes dentro de la franja de protección, esta cobertura es determinada por casas de habitación, locales industriales como tallares mecánicos e infraestructura vial, incluido los puentes. Aquí la contaminación puede ser constante y persistente por los diferentes vertidos o desechos depositados en el margen. Sin embargo, persisten algunas zonas con herbazal arbolado $(16 \%)$ en la zona antepuesta al casco urbano. Aguas abajo la vegetación disminuye predominando los pastizales con borde arbustivo (21\%) y zona descubierta (12\%). Ver mapa 4.

Para evitar un avance en la perdida de cobertura a lo largo de la cuenca, se recomienda la implementación de esfuerzos de restauración 
que tomen en cuenta tanto las características físicas y biológicas del sitio, así como aspectos sociales como el estilo de vida de las personas que habitan estas zonas y sus necesidades (Romero et. al., 2014). Por lo tanto, para poner en acción medidas de restauración en la parte media y baja de la cuenca (Sección II y III) se debe tomar en cuenta la opinión y participación activa de las comunidades aledañas con el fin de empoderar a los habitantes de este tipo de procesos y lograr transmitir la importancia e impacto que podrían tener, siempre tomando en cuenta que en estas secciones de la cuenca hay una mayor interacción con el cauce del río, debido a la proximidad tanto de cultivos como de infraestructura urbana.

Caracterización de la sucesión: El bosque denso presentó pendientes entre $21.59^{\circ}$ y $31.63^{\circ}$, el bosque ralo mostró una pendiente menor $\left(15.19^{\circ}\right)$, mientras que el herbazal arbolado era plano o con una pendiente del terreno muy baja.

Por otra parte, como se esperaba la mayor cobertura arbórea se presentó en el bosque denso (BD), $88.55 \pm 0.57(\% \pm \mathrm{DE})$, seguida del bosque ralo (BR) $73.5 \pm 9(\% \pm \mathrm{DE})$, y por último el herbazal arbolado (HA) 54.16 $\pm 1.17(\% \pm \mathrm{DE})$, esto debido a que la densidad arbórea disminuye según la clasificación previamente asignada.

Para las alturas se observó que el HA, tiene pocos individuos con alturas mayores a $24 \mathrm{~m}$, el BR presentó la mayoría de individuos entre los 17.47-23.91 m, mientras que en el $\mathrm{BD}$, los árboles son los más altos de las tres coberturas pero con varios individuos en las categorías más bajas (Gráfico 2). 
David Mattey-Trigueros, Jonathan Navarro-Picado, Priscilla Obando-Rodríguez, Alicia Fonseca-Sánchez, Christian Núñez-Solís. Caracterización de la cobertura vegetal dentro de la franja de protección del río Copey, Jacó, Puntarenas, Costa Rica.

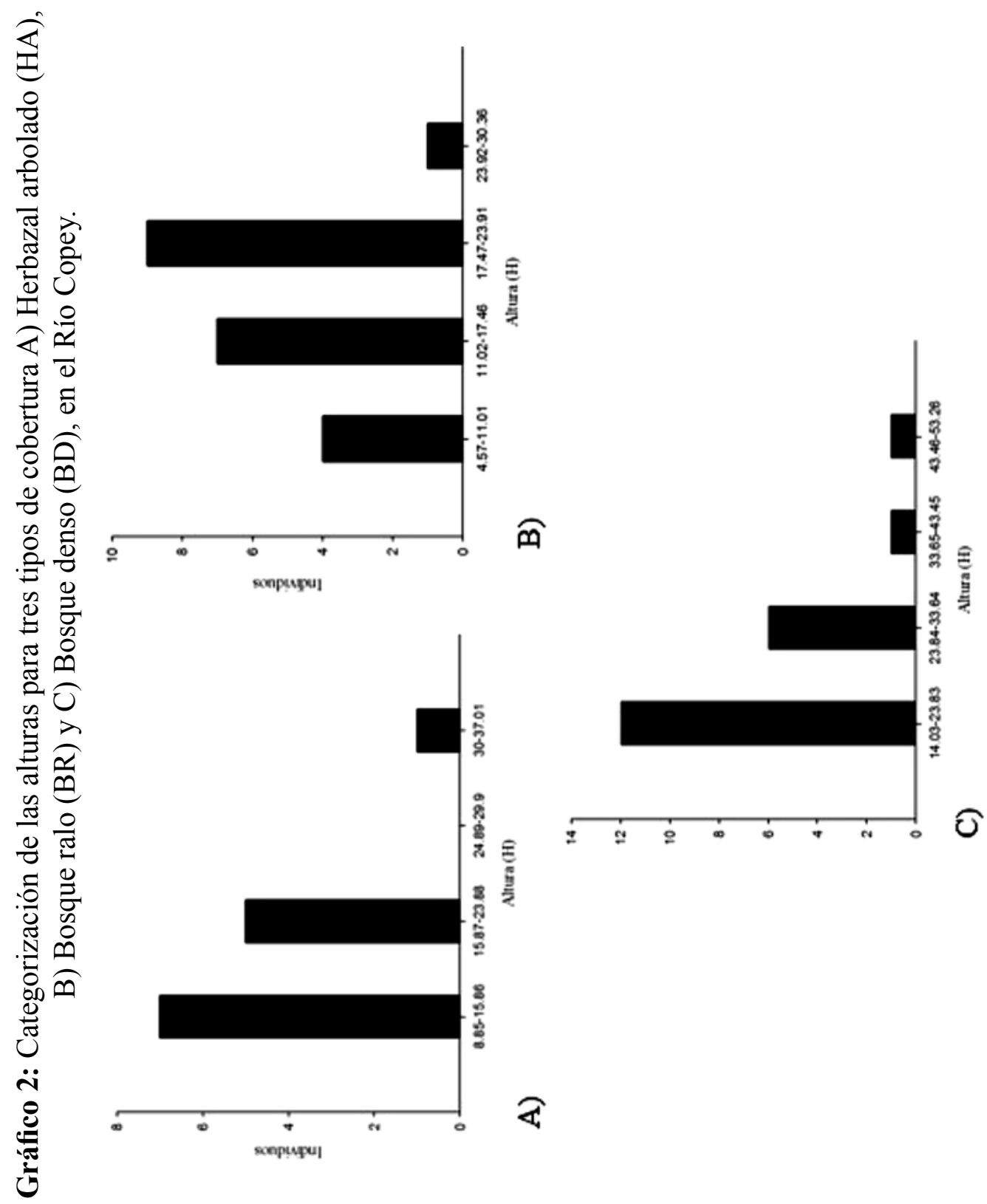


Las clases diamétricas muestran una dominancia de los DAP entre 10.2- 45.23 m para el HA, mientras que en los otros dos tipos de cobertura se observa una mayor homogeneidad en las clases diamétricas (Gráfico 3).

A pesar de estas diferencias encontradas entre los sitios con respecto a la cantidad de individuos encontrados, los datos tanto de alturas como DAP nos muestran zonas en donde aún se encuentran en etapas de sucesión tempranas probablemente por procesos de tala y alteraciones presentados en el pasado, esto se ve reflejado en alturas por debajo de los $24 \mathrm{~m}, \mathrm{y}$ que para esta zona del país no representan una asociación vegetal madura (más de 60 años) en donde los árboles se espera alcancen más de $50 \mathrm{~m}$ de altura (Quesada-Monge, 2008).

\section{Conclusiones}

El presente estudio, permite reconocer tres condiciones a lo largo del río Copey. La parte alta presenta zonas en las cuales se mantiene la zona protectora en las cercanías del cauce, la parte media proporciona una sección aprovechable para la siembra de árboles y posterior regeneración, ya que predominan herbazales o bosques secundarios intervenidos; por último, se pudo visualizar la parte baja del río como la sección más degradada y mayor presencia de actividad humana, tanto cultivos como asentamientos urbanos.

En la zona media del cauce se puede observar una gran área desprovista de vegetación, pero, de igual manera sin infraestructura urbana, lo cual nos indica que es una de las zonas de mayor potencial para esfuerzos de restauración, por lo que se recomienda determinar las principales presiones en estas zonas, así como la delimitación de zonas adecuadas para proyectos de restauración y determinar el grado de degradación de estas zonas (Romero et al., 2014).

En la zona media de este cauce un sector es el principal foco de contaminación tanto por aguas negras como por residuos sólidos, el cual está ubicado en el sector más cercano a un caserío, por lo que se recomienda un trabajo especial con esta comunidad con el objetivo de disminuir el impacto sobre el recurso hídrico y de igual manera con el fin de disminuir el riesgo de esta comunidad ante un eventual desastre natural debido a su vulnerabilidad por su cercanía al río. 
David Mattey-Trigueros, Jonathan Navarro-Picado, Priscilla Obando-Rodríguez, Alicia Fonseca-Sánchez, Christian Núñez-Solís. Caracterización de la cobertura vegetal dentro de la franja de protección del río Copey, Jacó, Puntarenas, Costa Rica.

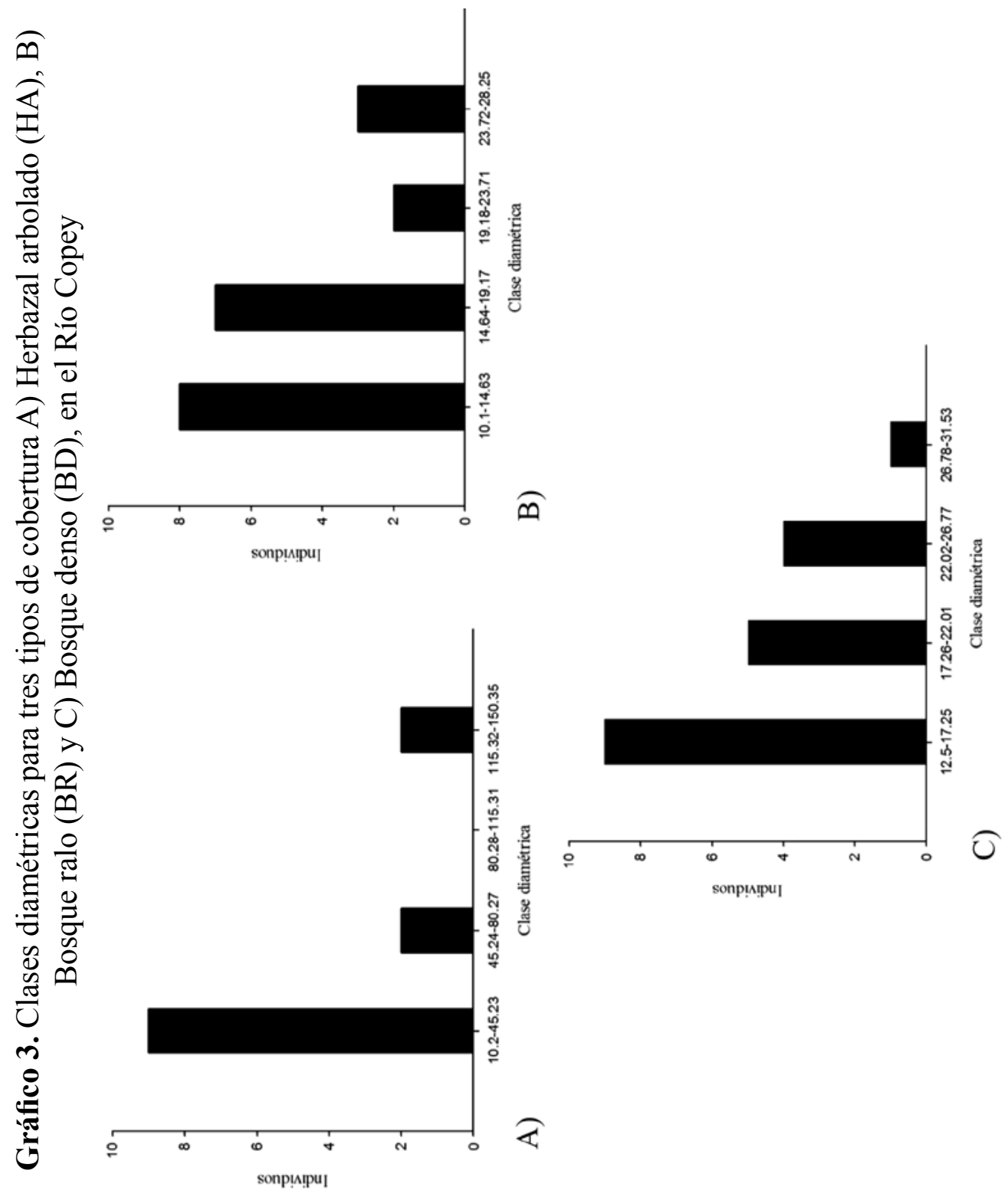


David Mattey-Trigueros, Jonathan Navarro-Picado, Priscilla Obando-Rodríguez, Alicia

Fonseca-Sánchez, Christian Núñez-Solís. Characterization of vegetation cover and land use

within the buffer zone of Copey river, Jacó, Puntarenas, Costa Rica.

\section{Referencias}

Arcos, I., Jiménez, F., Harvey, C. y Casanoves, F. (2007). Riqueza y abundancia de aves en bosques ribereños de diferentes anchos en la microcuenca del río Sesesmiles, Copán, Honduras. Revista Biología Tropical, 56(1), 355-369.

Arcos, I. (2005). Efecto del ancho los ecosistemas riparios en la conservación de la calidad de agua y la biodiversidad en la microcuenca del río Sesesmiles, Copán, Honduras. Tesis De Maestría. Centro Agronómico Tropical de Investigación y Enseñanza, Turrialba, Costa Rica.

Broadmeadow, S. y Nisbet, T. (2004). The effects of riparian forest managemente on the freshwater environment: a literature review of best management practice. Hydrology \& Earth System Sciences, 8 (3), 286-305.

Cardona, J. (2003). Calidad y riesgo de las aguas superficiales en la micorcuenca del Río La Soledad, Valle de Angeles, Honduras. Tesis de Maestría. Centro Agronómico Tropical de Investigación y Enseñanza, Turrialba, Costa Rica.

Ceccon, E. (2003). Los bosques ribereños y la restauración y conservación de las cuencas hidrográficas. Ciencias 72, 46-53.

Chará, J., Giraldo, L., Chará-Serna, A. y Pedraza, G. (2011). Beneficios de los corredores ribereños de Guadua angustifolia en la protección de ambientes acuáticos en la Ecorregión cafetera de Colombia. Recursos Naturales y Ambientes 61, 60-66.

Eichner, T. (2002). Ackerly Creek: Riparian buffer survey, Pennsylvania, Keystone College's Willary Water Discovery Center. 18p.

Elosegi, A. y Díez, J. (2009). La vegetación terrestre asociada al río: el bosque de ribera. En: Conceptos y técnicas en ecología fluvial. Fundación BBVA. Bilbao, España.

FAO. (2010). Evaluación de los recursos forestales mundiales 2010: Informe principal (Informe general). FRA2010/041 (p.346). Roma, Italia: Organización de las Naciones Unidas para la Agricultura y la Alimentación (FAO).

Gayoso, J. y Gayoso, S. (2003). Diseño de zonas ribereñas requerimientos de un ancho mínimo. Universidad Austral de Chile, Valdivia, Chile. 
Granados-Sánchez, D., Hernández-García, M. y López-Ríos, G. (2006). Ecología de las Zonas Ribereñas. Revista Chapingo Serie Ciencias Forestales y del Ambiente 12, 55-69.

Instituto Geográfico Nacional. (1986). Hoja cartográfica Herradura. Escala 1:500000. Proyección Lambert Norte, datum Clarck 1866. Impresión: Editora IGN. San José, Costa Rica.

Kutschker, A., Brand, C. y Miserendino, M. L. (2009). Evaluación de la calidad de los bosques de ribera en ríos del NO del Chubut sometidos a distintos usos de la tierra. Asociación Argentina de Ecología. Ecología Austral 19, 19-34.

Ley Forestal No 7575 (1996). En Gaceta Oficial No 72 . La asamblea legislativa de la República de Costa Rica.

MAG. (1991). Mapa de capacidad de uso del suelo para Costa Rica. Escala 1:200000. Proyección Lambert Norte, datum Clarck 1866. Impresión: Secretaria Ejecutiva de Planificación Sectorial Agropecuaria (SEPSA). San José, Costa Rica.

Meli, P. (2003). Restauración ecológica de bosques tropicales. Veinte años de investigación académica. Interciencia 28(10), 581-589.

Ortiz-Arrona, C. I., Gerritsen, P. R. W., Martínez, L. M., Allen, A. y Snoep, M. (2005). Restauración de bosques ribereños en paisajes antropogénicos, en el occidente de México. Simposio Internacional sobre Restauración Ecológica. Villa Clara, Cuba.

Peraza, M. (2009). Evaluación de la zona de recarga hídrica y bosques ribereños en la Subcuenca del Río Cumes, Jesús de Otoro, Intibucá, Honduras. Tesis de Licenciatura. Carrera de desarrollo socioeconómico y ambiente. Zamorano, Honduras.

Programa Araucaria. (2001). Caracterización de la vegetación de la cuenca del Río Savegre. (Informe final). Santo Domingo, Costa Rica: Instituto Nacional de Biodiversidad.

Proyecto de Regularización Catastral y Registral (PRCR). (2005-2008). Cartografia digital de Costa Rica. Escala: 1:5000. Proyección: CRTM05, datum WGS84. Registro Nacional. San José, Costa Rica. Quesada-Monge, R. (2008). Manual para promover la regeneración natural en pastos degradados en el Pacífico Central y Norte de Costa Rica. Corporación Garro y Moya. 63 p. 
Reglamento a la Ley Forestal (1997). La Gaceta N 16 . La Asamblea Legislativa de la República de Costa Rica.

Romero, F., Cozano, M., Gangas R. y Naulin, P. (2014). Zonas ribereñas: protección, restauración y contexto legal en Chile. Bosque 35 (1), 3-12.

Sirombra, M. y Mesa, L. (2010). Composición florística y distribución de los bosques ribereños subtropicales andinos del río Lules, Tucumán, Argentina. Revista Biología Tropical, 58, 499-510.

Viana, M., Amorós, E., Romero, G., Larenas, G. y Mamaní, Y. (2005). Ecología urbana: diagnóstico sanitario- ambiental en tres sectores del sistema ribereño Arias- Arenales. Informes Técnicos del Instituto de Ecología y Ambiente Humano. 